\title{
Participatory action research in two communities in Bolivia and the United States
}

\section{Rosemary Sarri and Catherine Sarri}

\section{Introduction}

Despite statements of significant global economic and social progress, the divisions between the world's haves and have-nots grow. According to the Overseas Development Council, nearly 1 billion men, women and children live in conditions of unmitigated poverty, fighting a daily battle against malnutrition, disease, illiteracy and infant mortality (Buvinic and Yudelman, 1989). Although these problems are most serious in developing countries, they are aslo present in postindustrial countries where poverty has increased greatly among minorities, especially women and children. New approaches are being considered to narrow the ever widening gap between the haves and have-nots (Campfens, 1990). One approach is participatory action research that seeks to reduce the distinction between the researcher and the researched by incorporating them in a collaborative effort of knowledge creation that will lead to community betterment. Action research is a process for gaining knowledge and taking action. Participatory action research goes one step further by seeking to redress inequity and redistribute power (Rapaport, 1985; Bookman and Morgen, 1988; Gaventa, in press).

This article examines the process and products of two case studies which utilized a participatory action research approach to: (1) identify community needs and develop activities for addressing those needs in a small rural community in Bolivia - Mallco Rancho; and (2) evaluate service-based programmes for adolescent youth and their families in Detroit, Michigan. ${ }^{1}$ The projects sought to overcome resistance of individuals, organizations and communities to new ideas and practices by: (1) incorporating the active participation of community members affected by the problems; (2) combining research and intervention strategies; (3) building local skills and

\footnotetext{
Rosemary C. Sarri is Professor of Social Work and Researcher at the Institute for Social Research, Univeristy of Michigan, Ann Arbor, MI, USA: Catherine M. Sarri, $\mathrm{MPH}$, is at the Alice Hamilton Occupational Health Center, Washington, DC.
}

International Social Work (SAGE, London, Newbury Park and New Delhi), Vol. 35 (1992), 267-80. 
leadership to sustain the changes; and (4) facilitating the development of co-operative working relationships between service agencies, researchers and community residents.

\section{Action research approach}

Action research methods were selected as the most appropriate strategy for improving the likelihood of change being sustained in Mallco Rancho and Detroit (Israel et al., 1989; Marti-Costa and Serrano-Garcia, 1983). By actively involving community members in the management of knowledge generation and change, action research methods are less likely to encounter resistance and more likely to produce sustained social and behavioural change (Schorr, 1988; Gutierrez, 1990). As Kaluzny et al. (1986) say:

... [people] who are involved in the recognition of a problem will be more likely to assist in identifying solutions to the problem. Similarly, those who are involved in the identification of potential solutions will be more willing to work towards implementing the solutions and institutionalizing the selected intervention.

The failure to integrate the active ongoing involvement of the participants in the research-change process contributes to a powerful resistance to change. As a result these planned change efforts often achieve only superficial compliance from the participants (Elden, 1983, 1986).

The action research approach involves researchers and community members in a collaborative, co-learning process which integrates investigation with education and collective action. These strategies are based on the premise that the active involvement of those affected by a problem is essential for meaningful problem-posing and problem-solving (Bruss and Macedo, 1985; Gaventa, 1989).

Kurt Lewin, considered by many as the pioneer of action research, describes it as a cyclical process of fact finding, action, evaluation and feedback (Lewin, 1946; Rapaport, 1985). For Lewin, action research methodology incorporates principles of group dynamics in the conduct of problem-solving and knowledge-building (Ketterer et al., 1980). This approach to investigation proceeds through a cycle of five phases: assessment of needs, action planning, action implementation, evaluation and specifying learning (Israel et al., 1989; Cunningham, 1985). The participatory action research paradigm owes much to the critical theorists who emphasize the dialectics of theory and practice along with the political role of scientific knowledge production (Freire, 1973; Horton, 1990; Lather, 1986). 
In summary, participatory action research strategies have the following characteristics:

1. They emphasize participation and collaboration where researchers and participants are co-learners in the research-change process. Community members are actively involved in all aspects of the research and action efforts - in identifying needs, in planning, implementing and evaluating solutions. Moreover, priority is given to addressing the issues and conditions identified by the community at large (Israel et al., 1989; Rogers, 1973).

2. They recognize the experiences and knowledge of community members as valid. Such an experiential learning effort encourages members to explore and reflect on their experiences and perspectives of their situation and environment. In this way, interventions can be made compatible with cultural and organizational values (Zaltman and Duncan, 1977).

3. They empower individuals and communities to act on their own behalf, by lessening their dependence on external forces and by developing local leadership and skills to identify and solve problems on an ongoing basis. This strategy facilitates community members gaining a greater critical awareness about their situation which is in turn used to cultivate resources and strategies to change the social system (Freire, 1973).

4. They reject notions of scientific objectivity and neutrality, seeking instead to alter existing power relations and increase the access of community members to knowledge and skills typically monopolized by researchers. Gaventa (in press) emphasizes that participation in knowledge generation demystifies the myth of expertise and develops a sense of ownership.

\section{Action research in the Bolivian context}

Action research strategies are particularly well suited to the Bolivan context. The majority of Bolivians live in conditions of unmitigated poverty, the result of years of social polarization, economic recession and poor distribution of meagre public services (Sanders, 1985). Additionally, Bolivia's vertical, sociopolitical power structure, which has traditionally been divided along ethnic, class and political lines, has limited the participation of poor Bolivians in political, economic and social activities (Barrios de Chungara, 1978; Wynia, 1978).

The increasing lack of confidence in formal (political, social) institutions in meeting the needs of the vast majority led to popular movements to confront their poverty and relative powerlessness. 
Examples of collective organizing are: communal kitchens, the proliferation of consumer and production co-operatives and the growth of political organizations to address the very basic needs of the poor (Werner, 1980; Barrios de Chungara, 1978; Tendler, 1983; Davidson and Stein, 1988).

In this context, the project consultant (one of the authors), community members and staff from a local non-profit organization completed a needs assessment in Mallco Rancho, a small, poor, rural agricultural community located outside the urban centre of Cochabamba, Bolivia. The people of Mallco Rancho are confronted by many of the same problems facing the majority of rural Bolivians: poverty, illiteracy, few opportunities for lucrative employment and high rates of morbidity from preventable diseases.

\section{Research and intervention goals}

The needs assessment was conducted in conjunction with the Association of Health Programmes in Rural Areas (APSAR) and a group of community members. APSAR is a local non-profit organization that has worked with the community of Mallco Rancho for four years in strengthening the capacity of the rural poor to meet their own needs by integrating improvements in health, education, agriculture, community development and leadership. The specific goals of the needs assessment were to:

1. Specify unmet needs (individual and collective);

2. Build the capacity of the community to recognize the socioeconomic and political causes of community needs, and to develop and implement collective efforts to address these; and,

3. Create a collaborative relationship between the researcher and community members that would facilitate co-learning and collaboration.

\section{Assessment of needs}

The action research model used in Mallco Rancho was based on models described by Marti-Costa and Serrano-Garcia (1983), Israel et al. (1989) and Werner (1980) and proceeded through a cyclical process of four phases: familiarization with community needs, action planning, implementation and evaluation.

First, the project consultant and APSAR staff became familiar with the community through a review of written materials and conversations with community residents, service providers and key 
community leaders. They used this information to identify community members interested in working on the needs assessment.

A core group consisting of five community members, the project consultant, and two APSAR staff persons was formed to carry out the necessary tasks. The group included men and women, farmers and professionals, of a variety of ages. It was believed that the core group would further research and intervention goals by strengthening commitment, facilitating skill development through modelling and developing local leadership. The core group was also responsible for informing the larger community about the results of the needs assessment at a community forum.

A variety of social economic, political and environmental factors contribute to underdevelopment. For this reason, the core group decided to use several different methods to assess local needs and possible interventions (Patton, 1980).

1. Participant observation: Attention was given to the social, economic and political environments; community activities (what was and was not taking place); and patterns of interactions among residents and between residents and service providers.

2. Citizen surveys: A survey, developed and administered by the residents of Mallco Rancho, elicited residents' perspectives on individual and collective needs and community resources. The survey provoked discussion of collective problems related to health, education and training and income generation.

3. Community forum: All community residents were invited to express their views on collective needs, current projects and plans to remedy perceived problems at a community meeting. Community interest in a consumers' co-operative and nutrition education arose out of forums and classes held with mothers' clubs.

4. Semi-structured interviews: Interviews were conducted with key community informants such as service providers, decision-makers (presidents of community organizations, political officials, business owners, etc.), and community organizations to identify participants for the action research 'core group' and to gain an understanding of individual perceptions of collective needs.

\section{Action planning}

In this phase, the core group developed goals and action plans based on analysis of needs and priority concerns within the community. At a community meeting the core group recommended action plans to gain support and guidance for activities. Based on the findings from 
the needs assessment the core group identified three primary community needs: income generation, training and health improvements. These needs were discussed at the community meeting where it was decided that collective efforts should promote income generation and health in the form of a consumer's co-operative and nutrition education through the mother's clubs. The community as a whole decided that opening a consumers' co-operative in Mallco Rancho would make nutritious foods available and affordable and increase income-generating opportunities.

\section{Action taking}

Following community approval the core group began implementation of the consumer co-operative and nutrition education. The core group developed a grant proposal with the project consultant and APSAR to provide seed money for the project. The grant addressed activities that were geared towards improving health status and income-generating opportunities of the community including: working with the staff of the local clinic to provide bi-weekly nutrition classes to mothers and conducting monthly growth monitoring of the health of children aged up to five; providing training for community members about the operation and maintenance of a consumers' co-operative; and establishing a system of consumers' and production co-operatives which would generate income for the whole community.

Additionally, the core group, interested community members, APSAR staff and the project consultant held weekly roundtable discussions where the people assembled examined their experiences and analysed how the social structure operates to sustain poverty and dependence among poor rural communities in Bolivia. In this way the participants developed a new critical consciousness about their situation and the need for social action.

\section{Project outcomes}

The first intention of the project was to engage researchers and community members in a collaborative, co-learning process to identify community needs and to develop strategies for confronting those problems. Community members administered a survey and the resulting sociodemographic information was fed back to the larger community for comments and modifications. Community members, the project consultant and APSAR staff pooled their knowledge and skills to generate results. 
Second, the research-intervention project generated new learning and collective action in problem-solving. Community members were not only actively involved in the needs assessment process, but they also controlled the process of evaluating needs worthy of collective action in implementing solutions. The core group was responsible for action planning and action implementation with ongoing support from the project consultant and APSAR staff.

Third, though experiential learning activities geared at skill development, the community was able to use the needs assessment information to develop strategies for implementing and institutionalizing the selected interventions of nutritional improvement, training and income generation. Community members sought training that would enable them to prepare more nutritional food, manage the affairs of the consumers' co-operative and conduct ongoing assessments of community needs.

Through training and skills development, the community was able to gain greater control over those resources that would sustain and institutionalize the project. Much of the community dialogue centred around the need to change existing social structures in order to shift the balance of decision-making and the inability of the community to access government resources and services that would help them to alleviate their poverty.

The community is still involved in the action implementation stage of the project. Although seed money has been meagre, the community continues to conduct nutrition classes and child growth monitoring sessions, to hold community meetings to inform residents of the status of the co-operative and to provide skill development for cooperative members.

\section{Action research in the Detroit context}

The Detroit project was located in a large industrial centre, a sharp contrast to a rural village in Bolivia, but the relative deprivation being experienced by its poor, and especially its youth, is at least as serious. Because participatory action research methods have the potential to empower disadvantaged and alienated citizens, they were viewed as desirable for the later stages of ongoing evaluation of a programme for delinquent adolescents in the city of Detroit. Since the early 1970s the city of Detroit, one of the major industrial cities of the US, has experienced a continuing economic decline and deindustrialization, accompanied by increasing racial segregation and crime associated with a serious problem of drug sales and abuse. 


\section{International Social Work}

\section{Project background}

Within this environment of urban disorganization and conflict, one of the authors was asked by a local agency to evaluate two rehabilitative programmes for adolescents who were committed to the care of the agency because of serious delinquent behaviour. After more than a year of assessment, using traditional evaluation methods, the findings revealed serious shortcomings in the ways in which the programmes related to the community in which they were located and where the youth resided. Youth responded favourably to the programmes while they were directly involved, but after release they became reinvolved in delinquency, largely because there was continuing crime in their neighbourhoods.

After consultation with agency staff, who had been kept informed of the findings throughout the research, it was mutually decided to implement a participatory action research approach so that changes in community structures could be targeted, along with the behaviour of adolescents. Some of the staff were initially hesitant, fearing loss of control of the programme.

At this same time, several other organizations and community leaders in the area invited the agency staff and researchers to join in forming a community coalition. They became participants in needs assessment and planning on a more comprehensive basis for the area. Several of the community coalition members were active proponents of a more thorough-going community development effort that would actively involve community residents. The researchers took an active part in facilitating the development of the coalition and in advising them on conducting the preliminary survey of community needs and resources.

\section{Research and intervention goals}

Using the information gained from the evaluation in the pre-action research phase as a guide, several goals were established by the community coalition and by the agency:

1. Identify unmet needs in the community and restructure services to meet those needs;

2. Increase utilization of the findings from local research;

3. Involve resident parents and youth in assessment and programme development;

4. Generate knowledge that would promote community development and participation; 
5. Secure resources for projects proposed by the residents, agency staff and community coalition members.

\section{Assessment of community needs and resources}

This stage in the action research model included accumulation of sociodemographic information about the area, along with specific assessment of the target adolescents and families. Multiple methods were employed to obtain this preliminary assessment, including:

1. Surveys by adolescents and parents along with the researchers to obtain an assessment of the community's needs, opportunities and future expectations;

2. Use of secondary data to obtain longitudinal information about experience of residents in service and justice systems;

3. Participant observation of community and agency activities by community residents and researchers.

This stage required several months of community organization and training of adolescents and parents for their roles in the project.

\section{Action planning}

Activities of the community coalition were planned in accord with the findings from the evaluation completed by the researchers and also with findings from separate needs assessments completed by others in the coalition. Regular meetings of the coalition soon revealed that there were very serious problems associated with crack-cocaine abuse and distribution, as well as with community programmes for adolescents and their parents. They agreed to recruit neighbourhood residents to participate in programme planning and development.

The researchers informed agency staff about the availability of a substance abuse primary prevention grant for high-risk adolescents, and the decision was made to apply for it. They were successful in receiving the grant, and the availability of resources made it possible to implement activities in accord with the evaluation findings that argued for community development as well as active participation of parents and adolescents in programme decision-making. Contacts were made with the city government and local churches in an effort to secure a building for a community centre.

\section{Action taking}

During the next year, the financial support from the local agency, city government and a church, a variety of activities got underway:

1. A community centre was opened with a small restaurant 
operated by youth and agency staff; a clothing distribution centre; and a sports and tutorial programme.

2. Local church and school personnel were organized to assist with the substance abuse programme and business persons were contacted for youth vocational training and employment opportunities.

3. Open community meetings were held to which neighbourhood parents came to express their concerns and preferences.

4. An advisory steering committee was formed in the immediate neighbourhood of the community centre, including parents, adolescents, business persons, ministers and school personnel.

This approach to the development of community services represented something entirely new for most of the residents who had never before been active participants in planning and development programmes. It was also new for the agency staff. The researchers took on an active role in the early stages, but that diminished as the residents and staff assumed greater responsibility. It was clear, however, that the process would be lengthy and would require ongoing support and assistance if it were to succeed.

At the time of writing this article, one year had passed since the recommendation had been made by the researchers to the staff that a more participatory action research effort be undertaken. It is too early to measure any final outcomes, but several intermediary steps have been completed, and enthusiasm is still growing. Some progress has been made in attaining the goals that were initially established:

1. Several community needs were identified through the work of the community coalition and the review of findings from the surveys and evaluation results.

2. Findings from the research are being utilized in the design of new programmes, in training people for participation and in furthering the links with the community coalition.

3. Adolescents are being trained to do other community needs assessments and to work with younger children. Planning is underway to involve parents and adolescents in joint planning of activities.

4. Knowledge has been generated about community development in a very deprived neighbourhood. It is anticipated that this knowledge will be codified within the next year for utilization by other neighbourhood groups.

\section{Discussion}

Although the Bolivian and Detroit projects were implemented in very different environments, the accomplishments of both projects 
demonstrate that action research strategies can successfully generate new knowledge. This point has been illustrated in several ways.

First, it was shown that action research methods can be used to involve community residents in identifying community needs, developing activities to address identified needs and in implementing activities. By incorporating indigenous involvement in all phases of assessment, action planning and action taking, these projects were able to generate greater community ownership of the project while lessening the possibility that the communities would resist or reject new ideas and practices. Community ownership was manifested in sustained involvement of members, including adolescents, in activities that continued beyond the life of the project. Additionally, increased willingness of community members to develop the knowledge and skills to adopt greater leadership roles is indicative of a long-term commitment to the spirit of collaborative effort.

Second, collaboration between the researchers and community residents in the process of social transformation required that the professional abandon the spectator role and commit him-/herself to addressing the felt needs of the disadvantaged and powerless. To reject 'scientific neutrality' and positivism recognizes that all events take place within a political-cultural context and that the people who directly experience a social problem must be actively involved in its analysis and resolution.

Third, in both projects the knowledge development process was demystified as the participants acquired information and skills that could be used in describing local needs. The participants learned that there are biases, fallibility, conflicting views and explanations.

Fourth, the projects demonstrated that a co-learning process in which researchers, community residents and staff work together can generate solutions and action. Participants in both projects developed research, problem analysis, group problem-solving and technical skills that can be used in the ongoing analysis and resolution of local problems. Knowledge and skills, which are often 'monopolized' by researchers and academics, can be readily incorporated by community residents. There are, however, continuing roles for researchers in facilitating ongoing innovation and assessment of the processes and products.

Fifth, in the two projects knowledge development by those who directly experience the problem was viewed by participants as an essential part of social action. They developed a new consciousness of how the social structures operated and how they could be changed. 
We have not considered the shortcomings of this participatory approach but there are obviously several that should be taken into consideration. Although it is more directly apparent in Bolivia, work and daily survival requirements were constraints on participation in both projects. Second, time requirements are substantial, and the process cannot be rushed if it is to be effective in helping people become empowered. Third, powerful professional, systemic and political factors in the larger environment may inevitably constrain the effective development of participatory approaches. Lastly, more thought must be given to the provision of resources to facilitate the active participation of community residents.

\section{Conclusion}

Action research in the context of community development is an alternative to social work intervention. The research achieves lasting social change because the level of intervention is at the community rather than individual level and because of the nature of the goals that are sought. Control of social action rests with the community which is actively involved in addressing its needs, thereby increasing the possibility that the change will be adopted and will be long lasting.

Action research strategies present a substantial challenge to social work educators as they train tomorrow's social workers to integrate research and practice that is directed towards social transformation of inner cities, impoverished rural areas and oppressed populations. This is a joint endeavour that is often neglected in the intervention approaches that have been dominant in the past quarter century.

Barbara Solomon quoted by Gaventa (in press) points out that the empowerment approach is essential for social transformation because most persons with whom public social workers are involved with are poor, marginal and disadvantaged. These residents have had little or no opportunity to develop the knowledge and skills that are necessary for their active participation or to become 'knowledge producers' and thereby to exercise greater control over their lives. All too often social work intervention has operated to maintain the status quo. Clearly, the experience of these two projects, although as yet incomplete, demonstrates that alternative approaches in which community residents are actively involved in all aspects of decision-making provide an excellent opportunity to change social welfare institutions and social work practice.

An important outcome of sustained community development is to lay a foundation for democratic participation of all persons. Through 
enabling beneficiaries with the necessary knowledge and skills to identify and address their basic needs, it is possible to reduce their dependence on deficient public or private sector services that are often unable to meet their needs effectively.

Lastly, since we cannot expect that the 1990 s will be a time in which more resources become available for human services, participatory action research can allow the consumer an active role in setting the priorities and in controlling many aspects of service delivery so as to maximize the allocation of resources to populations in greater need. In turn, this participation is likely to have positive consequences in helping the impoverished and disadvantaged towards genuine empowerment.

\section{Note}

1. The Bolivian project was funded with grants from the University of North Carolina School for Public Health and the Partners for the Americas. The Michigan project was funded with grants from the Michigan Department of Social Services and Wolverine Human Services. The authors wish to express their appreciation to the funders and also to the many colleagues who provided so many helpful suggestions for the projects and for this article.

\section{References}

Barrios de Chungara, D. (1978) Let Me Speak! New York: Monthly Review Press.

Bookman, A. and S. Morgan (1988) Women and the Politics of Empowerment. Philadelphia, PA: Temple University Press.

Bruss, N. and D.P. Macedo (1985) 'Toward a Pedagogy of the Question: Conversations with Paolo Freire', Journal of Education 167(2).

Buvinic, M. and S. Yudelman (1989) Women, Poverty and Progress in the Third World. New York: Foreign Policy Association.

Campfens, H. (1990) 'Issues in Organizing Impoverished Women in Latin America', Social Development Issues 13(1).

Cunningham, B. (1985) 'Action Research: Toward a Procedural Model', Human Relations 29(3): 215-38.

Davidson, J.R. and S. Stein (1988) 'Economic Crisis, Social Polarization, and Community Participation in Health Care', in D.K. Zschock (ed.) Health Care in Peru. Boulder, CO: Westview.

Elden, M. (1983) 'Client as Consultant: Work Reform Through Participative Research', National Productivity Review (Spring).

Elden, M. (1986) 'Sociotechnical Systems as Public Policy in Norway: Empowering Participation through Order-managed Change', Journal of Applied Behavioral Science 22: 239-44.

Freire, P. (1973) Education for Critical Consciousness. New York: Continuum.

Gaventa, J. (1989) Participatory Research in North America. New Market, TN: The Highlander Center.

Gaventa, J. (in press) 'The Powerful, The Powerless and the Experts: Knowledge 
Struggles in an Information Age', in P. Park, B. Hall and T. Jackson (eds) Participatory Research in America.

Gutierrez, L. (1990) 'Working with Women of Color', Social Work 35(2): 149-54.

Horton, M. (1990) The Long Haul. New York: Doubleday.

Israel, B., S.J. Schurman and J.S. House (1989) 'Action Research on Occupational

Stress: Involving Workers as Research', International Journal of Health Research 19(1): 135-55.

Kaluzny, A.D., A. Schenk and T. Ricketts (1986) 'Cancer Prevention in the Workplace: An Organizational Innovation', Health Promotion 1(3): 293-9.

Ketterer, R.F., R.H. Price and P.E. Polister (1980) 'The Action Research Paradigm', in R.H. Price and P.E. Polister (eds) Evaluation and Action in the Social Environment. New York: Academic Press.

Lather, P. (1986) 'Research as Praxis’, Harvard Educational Review 56(3): 255-77.

Lewin, K. (1946) ‘Action Research and Minority Problems', Journal of Social Issues 2 : 34-46.

Marti-Costa, S. and I. Serrano-Garcia (1983) 'Needs Assessment and Community Development: An Ideological Perspective', Prevention in Human Services (Summer): 75-88.

Patton, M.Q. (1989) Qualitative Evaluation Methods. Newbury Park, CA: Sage.

Rapaport, R. (ed.) (1985) Children, Youth and Families: The Action-Research Relationship. New York: Cambridge University Press.

Rogers, E. (1973) 'Strategies for Linking Research and Use', in What Do We Know From Research About the Process of Research Utilization. Ames, IA: Iowa State University.

Sanders, D. (1985) The Struggle of Health. London: Macmillan.

Schorr, L. (1988) Within our Reach. New York: Doubleday.

Solomon, B. (1990) 'Rethinking Empowerment', Journal of Progressive Human Services 1(1): 27-39.

Tendler, J. (1983) What to Think about Cooperatives. Washington, DC: InterAmerican Foundation.

Werner, D. (1980) 'Community Organization and Rural Development: A Learning Process Approach', Public Administration Review (Sep./Oct.): 480-510.

Wynia, G.W. (1978) The Politics of Latin America Development. Cambridge: Cambridge University Press.

Zaltman, G. and R. Duncan (1977) Strategies for Planned Change. New York: Wiley. 